\title{
An Eight-Year Case Control Study Identifying Predictors of Adenoid Recurrence
}

Keywords: Adenoid; Adenoidectomy; Recurrence; Curette technique; Lateral neck x-ray

\section{Abstract}

Objectives: To determine the rate of revision adenoidectomy and to identify the risk factors associated with adenoid recurrence. In addition, we reviewed preoperative lateral neck $x$-Ray to see if adenoid size measurements could predict recurrence.

Design: A 1:1 matched retrospective case-control study.

Results: The rate of revision adenoidectomy was $2.74 \%$.The mean age at first adenoidectomy was significantly lower in the revision adenoidectomy group. There was a strong association between adenoidectomy without tonsillectomy and repeated adenoidectomy. In addition, a diagnosis of OSA and other medical disorders including bronchial asthma and allergic rhinitis was a strong predictor of revision surgery. Hypertrophy of adenoid based on endoscopic examination indicates that patients with large adenoid size were more likely to require repeated procedure.

Conclusion: We identified five risk factors for adenoid recurrence. Children younger than 5 years, patients with concurrent OSA, children who had undergone an adenoidectomy alone without tonsillectomy, concomitant diagnosis of medical disorders, and patients with large adenoid size on nasal endoscopy.

\section{Introduction}

Adenoidectomy is a frequently performed procedure in pediatric age group [1]. Regrowth of adenoid tissue is of concern to both the surgeon and the patient. There is scarce information in the literature regarding adenoid recurrence and its management [2]. Various risk factors of adenoid recurrence were discussed in literature including demographic data, preoperative endoscopic examination and lateral neck x-Ray findings, presence of other medical disorders including bronchial asthma and allergic rhinitis, presence of obstructive sleep apnea and concurrent tonsillectomy.

Our purpose was to determine the rate of revision adenoidectomy at our institution and to identify the risk factors associated with the need for revision surgery. In addition we wanted to check if preoperative lateral neck $\mathrm{x}$-Ray findings or size measurements could predict recurrence.

\section{Methods}

\section{Design: A retrospective case control study.}

Records of King Abdulaziz University hospital were reviewed and searched to identify all cases that underwent adenoidectomy or adenotonsillectomy between January 2006 to June 2013. We identified those who had revision procedure by going back to medical records and booked procedures as revision. Data including demographic data, clinical presentation, medical conditions, other procedures, concurrent tonsillectomy, and preoperative findings were collected.

\section{International Journal of} Otorhinolaryngology

\section{Alkhatib $\mathrm{T}^{1,2^{\star}}$, Khashoggi $\mathrm{K}^{3}$, Bukhari $\mathrm{AF}^{4}$, Malaikah $\mathrm{RH}^{5}$, Ageely $\mathrm{G}^{6}$, Khalifa $\mathbf{W M}^{7}$, Alnoury $\mathbf{I}^{8}$, Merdad $\mathbf{M}^{9}$ and Marzouki $\mathrm{H}^{10}$}

${ }_{1,4,5,7,8,9,10}$ Department of Otolaryngology-Head Neck Surgery, King Abdulaziz University, Saudi Arabia

${ }^{2}$ Vice dean, Ibn Sina national college for medical studies, Saudi Arabia

${ }^{3,6}$ Radiology Department, King Abdulaziz University, Saudi Arabia

\section{*Address for Correspondence}

Talal Alkhatib, Pediatric otolaryngologist Associate professor of Otolaryngology-Head neck surgery, King Abdulaziz University, Vice dean of medicine, Ibin Sina college, Jeddah, Saudi Arabia; E-mail: talkhatib@kau.edu.sa; talkhatib@gmail.com

Submission: 20 October, 2017

Accepted: 20 November, 2017

Published: 22 November, 2017

Copyright: ( 2017 Al-Khatib T, et al. This is an open access article distributed under the Creative Commons Attribution License, which permits unrestricted use, distribution, and reproduction in any medium, provided the original work is properly cited.

A case-control study was then performed by matching each child who had undergone a repeated adenoidectomy to an age-gendermatched child who had undergone a single adenoidectomy within 8 years of each case. The control medical charts were then reviewed, and their demographic information was collected into a database. The adenoid size was measured on lateral neck $\mathrm{x}$-ray performed prior to the first adenoidectomy in both groups and before the second adenoidectomy in the recurrence group. Adenoid size was defined as small if adenoid tissue filled $25 \%$ or less of the nasopharynx, medium if it filled $26 \%$ to $75 \%$ and large if it filled $76 \%$ or more .A straight line was drawn along the anterior margin of the basiocciput. From the point of the maximum adenoid shadow convexity, a second line was drawn perpendicular to the first one. The adenoid measurement

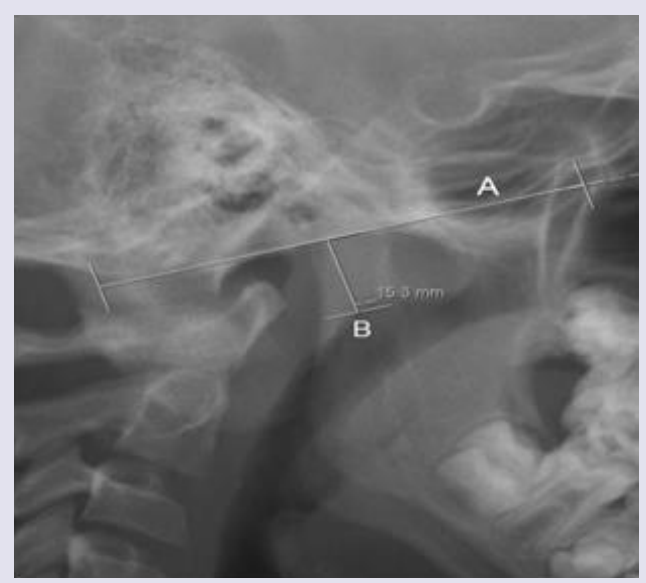

Figure 1: Adenoid hypertrophy measurements.

A straight line (A) was drawn along the anterior straight margin of the basiocciput. From the point of the maximum adenoid shadow convexity, a second line (B) was drawn perpendicular to the first one. The adenoid measurement represents the distance between the lines intersection and the point of the maximum adenoid shadow convexity (Fujioka et al.) [11]. 
Citation: Alkhatib T, Khashoggi K, Bukhari AF, Malaikah RH, Ageely G, et al. An Eight-Year Case Control Study Identifying Predictors of Adenoid Recurrence. Inter J Otorhinolaryngology. 2017;4(2): 4.

represented the distance between the lines intersection and the point of the maximum adenoid shadow convexity (Figure 1).

Statistical analyses were conducted using SPSS. Chi-square test, Person and Spearman Correlation and, Paired Samples Test were used for the statistical analysis. To identify risk factors associated with repeated adenoidectomy, data were analyzed using nonparametric methods. Data from the matched case-control study were analyzed using the McNemar test. $\mathrm{P}<.05$ was considered statistically significant. Ethical approval for this study was obtained from the Research Ethics Committee at King Abdulaziz University Hospital (KAUH).

\section{Results}

During the 8-year period of the review, 1468 adenoidectomies were performed for patients under age of 18 . Forty cases of repeated adenoidectomies were identified. The rate of repeated adenoidectomy was $2.74 \%(40 / 1468)$. All adenoidectomies were performed by curette technique. The distribution of characteristics within cases and controls are given in (Table 1). Out of 40 patients, twenty-four (60\%) were males and sixteen were females (40\%). The mean age at first procedure was 4.28 years (SD 3.320 years). The mean age at second procedure was 7.50 years (SD 3.320 years). The average interval between the first and second surgery was of 3.22 years.

The mean age at first adenoidectomy was significantly lower in the repeated adenoidectomy group and children younger than 5 years at the time of adenoidectomy were 2 times more likely to require a repeated procedure $(\mathrm{P}<.001)$.

In addition, there was a significant relationship between OSA and the chance of adenoid recurrence ( 0.25 times in comparing to nonOSA patients) $(\mathrm{p}=0.002)$.

Our results also showed that there is a significant relationship between certain Medical disorders including bronchial asthma, allergic rhinitis and the chance of adenoid recurrence. The percentage of Bronchial asthma among the recurrent group was 50\% (p-value of $<0.0005$ ). $27.5 \%$ of the recurrent group was diagnosed with allergic rhinitis (p-value of 0.002). Further, there was a strong association between adenoidectomy without tonsillectomy and repeated adenoidectomy, with children who had underwent adenoidectomy alone having a 2.5 times higher chance of having a repeated procedure $(\mathrm{p}<0.0005)$.

Regarding X-ray findings, a significant relationship was found between Adenoid size by endoscopic examination and the chance of revision adenoidectomy $(\mathrm{p}<0.0005)$. Large Adenoid size was found in $47.5 \%$ of recurrence group. On the other hand, lateral neck x-ray was performed for 13 patients in the control group out of 40 . X-ray was not performed or not available for 27 patients in the control group and 30 patients in the recurrence group. Of the 40 patients who had a revision adenoidectomy, only 10 patients underwent lateral neck $\mathrm{x}$-ray before the first operation and 16 had done $\mathrm{x}$-ray before the second operation. The mean adenoid size before the first adenoidectomy in the control group was $14.9 \mathrm{~mm}(\mathrm{SD} \pm 4.15 \mathrm{~mm})$, while the mean of the recurrence Group is $(18.3 \mathrm{~mm} \pm 4.4 \mathrm{~mm})$. The mean difference was $3.4 \mathrm{~mm}$ larger in the revision group. This difference is not statistically significant .For the recurrence group, the mean adenoid size before the first adenoidectomy was $18.3 \mathrm{~mm}$ (SD \pm $4.4 \mathrm{~mm}$ ) and the mean adenoid size before the second adenoidectomy was $14.17 \mathrm{~mm}(\mathrm{SD} \pm 2.13 \mathrm{~mm})$. The mean difference between the adenoid size before the first and second adenoidectomies was 4.13 $\mathrm{mm}$, which is statistically significant ( $\mathrm{p}$-value $=0.002$ ).

\section{Discussion}

According to our review, $2.7 \%$ of our patients undergoing adenoidectomy required revision surgery. Children younger than 5 years at the time of adenoidectomy were twice as likely to require revision surgery. Similar to our study, a published retrospective study on revision adenoidectomy, the mean age at presentation for primary adenoidectomy was 3.68 and was 7.69 years for secondary surgery with an average time interval of 4.3 years [2]. In another retrospective cohort study on the incidence of revision adenoidectomy in children, the mean age at first procedure was found to be 2.8 years. Mean age at second procedure was 4.7 years and the mean interval between procedures was 1.8 years [1]. Another cohort study on factors associated with revision adenoidectomy found that young age at initial adenoidectomy was a significant factor for revision

Table 1: Characteristics of children in matched case-control study.

\begin{tabular}{|c|c|c|c|c|}
\hline Characteristics & Cases $(n=20)$ & Control $(n=40)$ & Odds Ratio & P Value \\
\hline \multicolumn{5}{|l|}{ Age, $y$} \\
\hline Mean age of first procedure & 4.28 years & 4.28 years & NA & NA \\
\hline Mean age of second procedure & NA & 7.50 years & NA & NA \\
\hline \multicolumn{5}{|l|}{ Gender (male/female) } \\
\hline Males & $24 / 40(60 \%)$ & $24 / 40(60 \%)$ & NA & NA \\
\hline Frmales & $16 / 40(40 \%)$ & $16 / 40(40 \%)$ & NA & NA \\
\hline Bronchial asthma, & $4 / 40(10 \%)$ & $20 / 40(50 \%)$ & NA & $(p=0.000)$ \\
\hline allergic rhinitis & $1 / 40(2.5 \%)$ & $11 / 40(27.5 \%)$ & NA & $(p=0.002)$ \\
\hline OSA & $4 / 40(10 \%)$ & $16 / 40(40 \%)$ & 0.25 & $(p=0.002)$ \\
\hline \multicolumn{5}{|l|}{ Surgical procedure } \\
\hline adenoidectomy without tonsillectomy & $2 / 40(5 \%)$ & $25 / 40(62.5 \%)$ & 0.08 & $(p<0.0005)$ \\
\hline adenotonsillectomy & $38 / 40(95 \%)$ & $15 / 40(37.5 \%)$ & 2.533 & NA \\
\hline \multicolumn{5}{|l|}{ Adenoid size, Endoscopic exam } \\
\hline
\end{tabular}


adenoidectomy [3]. Another retrospective case-control study of repeated adenoidectomy in children found that children younger than 5 years at the time of adenoidectomy were 2.5 times more likely to require a repeated procedure [4].

In patients diagnosed with OSA, $40 \%$ experienced recurrence of adenoid symptoms and required repeated procedure. Our statistical results revealed a high statistically significant relationship between OSA and the chance of recurrence of adenoid ( $\mathrm{p}=0.002$ ), which may indicate an association between OSA and risk of recurrence. Perhaps large adenoids might have played a role in the recurrence rate since endoscopic evaluation of adenoid size in the current study found a strong association between large adenoid size and revision adenoidectomy, and considering that non-visualized curette technique was performed in all of the collected cases, this results may theorize that large adenoid size was the main contributor to OSA and recurrence of adenoid and perhaps adenoid tissue was not removed completely in the first surgery.

Our study identified a strong association between adenoidectomy without tonsillectomy and repeated adenoidectomy, with children who had undergone adenoidectomy alone having a 2.5 times higher chance $(\mathrm{p}<0.0005)$ of having a repeated procedure. In another case control study of repeated adenoidectomy, children who had undergone an adenoidectomy alone without tonsillectomy were 4.0 times more likely to require a repeated procedure compared to children with concurrent tonsillectomy [4].

Regarding the relationship between revision of adenoid and some medical disorders, half of the patients with revision adenoidectomy $(50 \%=20 / 40)$ were diagnosed with asthma. Others were diagnosed with allergic rhinitis $(27.5 \%=11 / 40)$. Our study illustrated a high statistically significant relationship between medical disorder including Bronchial asthma, allergic rhinitis and the chance of recurrence. The significant value among patients with allergic rhinitis $(\mathrm{p}-=0.002)$, and with patients with bronchial asthma $(\mathrm{p}=0.000)$ which indicated a high statistically significant relationship between both medical disorders and the chance of recurrence using chi-square test. In a study on factors associated with revision adenoidectomy, there was a high incidence of allergies (32\%), and bronchial asthma (23\%) among patients with revision adenoidectomy, which aligns with our Results [3].

Previous studies have argued that the adenoid size on endoscopic examination does not correlate with lateral neck x-ray findings. Regarding radiographic and endoscopic evaluation of adenoid size we found a strong association between large adenoid size and revision adenoidectomy, where $47.5 \%$ of the recurrence group were having large adenoid by endoscopic examination. In regards to radiological evaluation there was no significant statistical difference between the adenoid size on lateral neck x-ray in the recurrence and control groups. The x-ray were available only for $25 \%(10 / 40)$ of the recurrence group and $32 \%(13 / 40)$ of the control group as some of surgeons prefer not to do preoperative $\mathrm{x}$-ray and either depend on history or endoscopic assessment of the adenoid. The small size along with technical variation e.g patient position and radiation parameters (Kvp and mAs) may have contributed to this result. The size of the recurrent adenoid tissue was found to be smaller than the endoscopic examination by $4 \mathrm{~mm}$. In a study on comparison between radiological and endoscopic evaluation of adenoid size, adenoids evaluated endoscopically were on average $37.5 \%$ larger as compared to adenoids evaluated by lateral neck $\mathrm{x}$-ray and no adenoid was labelled as small endoscopically [5].

As illustrated in our study, all of the adenoidectomies were done by curette technique. No immediate post adenoid removal check was carried out. It has previously been suggested that curette technique or performing an adenoidectomy without visualization with a mirror or endoscope could be a risk factor for recurrence because it's carrying a risk of incomplete tissue removal [6]. Another study in which mirror visualization was performed, as assessed with palpation, an $80 \%$ rate of residual tissue requiring further removal was recognized [7]. In a study of a combined method of traditional curette and power-assisted endoscopic adenoidectomy, after conventional curette adenoidectomy, a significant mass of residual adenoid tissue is observed in about $50 \%$ of the cases. The combined approach of conventional curette and endoscopic adenoidectomy with microdebrider assured a complete and accurate removal of the adenoid tissue [8]. Another comparative study on conventional versus endoscopic adenoidectomy found that more than $50 \%$ residual adenoid tissue in the group who underwent curettage adenoidectomy [9]. In a published retrospective study of Suction diathermy for adenoidectomy, complications and risk of recurrence they found re-growth of adenoid tissue may occur despite visualisation of the nasopharynx at the time of surgery, and the incidence of re-growth is similar to that reported in patients undergoing conventional adenoidectomy by curettage [10].

Limitation to our study included that we were not unable to evaluate or follow up the recurrence of the cases required adenoidectomy once. In addition, we could not evaluate the benefit of undergoing a second adenoidectomy. Furthermore, we were limited to assess the rate of repeated adenoidectomy, and the retrospective nature of our study did not allow us to accurately collect information for all possible factors associated with this recurrence, and we have recorded those variables at one point in time so we can no detect weather the exposure or recurrence occur first. Some previous studies have suggested that gastroesophageal reflux and some allergies may lead to increase the rate of adenoid regrowth $[1,3,7]$ while we tried to gather these information from patient medical records, most of these information were not present [11-13]. The fact that all cases were done by curette technique did not allow us to suggest non-visualized technique as a risk factor. The lateral neck x-ray were available only for $25 \%$ (10/40) of the recurrent group and 32\% (13/40) of the control group, although endoscopic examination showed a strong association between large adenoid size and the rate of recurrence, we could not compare these results to $\mathrm{x}$ ray findings since there was a lot of missing data [14-16].

\section{Conclusion}

We identified five risk factors for adenoid recurrence post curette adenoidectomy. Children younger than 5 years at the time of adenoidectomy, patients with concurrent obstructive sleep apnea, Children who had undergone an adenoidectomy alone without tonsillectomy, concomitant diagnosis of bronchial asthma or allergic 
Citation: Alkhatib T, Khashoggi K, Bukhari AF, Malaikah RH, Ageely G, et al. An Eight-Year Case Control Study Identifying Predictors of Adenoid Recurrence. Inter J Otorhinolaryngology. 2017;4(2): 4.

rhinitis, and patients with large adenoid size based on endoscopic examination. Radiologic measurements preoperatively were not statistically significant predictors of recurrence. Further research should look into weather curette technique was the reason for leaving remnants of large adenoid tissue.

\section{References}

1. Monroy A, Behar P, Brodsky L (2008) Revision adenoidectomy-a retrospective study. Int J Pediatr Otorhinolaryngol 72: 565-570.

2. Kim SY, Lee WH, Rhee CS, Lee CH, Kim JW (2013) Regrowth of the adenoids after coblation adenoidectomy: cephalometric analysis. Laryngoscope 123 2567-2572.

3. Dearking AC, Lahr BD, Kuchena A, Orvidas LJ (2012) Factors associated with revision adenoidectomy. Otolaryngol Head Neck Surg 146: 984-990.

4. Duval M, Chung JC, Vaccani JP (2013) A case-control study of repeated adenoidectomy in children. JAMA Otolaryngol Head Neck Surg 139: 32-36.

5. Lourenço EA, Lopes Kde C, Pontes A jr, Oliveira MH, Umemura A, et al (2005) Comparison between radiological and nasopharyngolaryngoscopic assessment of adenoid tissue volume in mouth breathing children. Braz J Otorhinolaryngol 71: 23-27.

6. Ark N, Kurtaran H, Ugur KS, Yilmaz T, Ozboduroglu AA (2010) Comparison of adenoidectomy methods: examining with digital palpation vs visualizing the placement of the curette. Int J Pediatr Otorhinolaryngol 74: 649-651.

7. Joshua B, Bahar G, Sulkes J, Shpitzer T, Raveh E (2006) Adenoidectomy: long-term follow-up. Otolaryngol Head Neck Surg 135: 576-580.
8. Pagella F, Matti E, Colombo A, Giourgos G, Mira E (2009) How we do it: a combined method of traditional curette and power-assisted endoscopic adenoidectomy. Acta Otolaryngol 129: 556-558.

9. Datta R, Singh VP (2009) Conventional versus endoscopic powered adenoidectomy: a comparative study. Med J Armed Forces India 65: 308312.

10. Buchinsky FJ, Lowry MA, Isaacson G (2000) Do adenoids regrow after excision? Otolaryngol Head Neck Surg 123: 576-581.

11. Fujioka M, Young LW, Girdany BR (1979) Radiographic evaluation of adenoidal size in children: adenoidal-nasopharyngeal ratio. AJR Am J Roentgenol 133: 401-404.

12. Lesinskas E, Drigotas M (2009) The incidence of adenoidal regrowth after adenoidectomy and its effect on persistent nasal symptoms. Eur Arch Otorhinolaryngol 266: 469-473.

13. Liapi A, Dhanasekar G, Turner NO (2006) Role of revision adenoidectomy in paediatric otolaryngological practice. J Laryngol Otol 120: 219.

14. Bhattacharjee R, Choi BH, Gozal D, Mokhlesi B (2014) Association of adenotonsillectomy with asthma outcomes in children: a longitudinal database analysis. PLoS Med 11: e1001753.

15. Kovaleva LM (1994) Repeated adenoidectomy and prevention of the recurrence of adenoid hypertrophy. Vestn Otorinolaringol 1: 18-21.

16. Skilbeck CJ, Tweedie DJ, Lloyd-Thomas AR, Albert DM. Suction diathermy for adenoidectomy: complications and risk of recurrence. Int J Pediatr Otorhinolaryngol 71: 917-920. 